\title{
Licorice root. A natural sweetener and an important ingredient in Chinese medicine*
}

\author{
Isao Kitagawa \\ School of Pharmaceutical Sciences, Kinki University, 3-4-1 Kowakae, Higashi- \\ osaka, Osaka 577-8502, Japan
}

\begin{abstract}
This paper reviews our investigations on the chemical constituents of several kinds of botanically identified licorice roots, which led to the characterization of 13 then-new glucuronide-saponins named licorice-saponins (A-L), apioglycyrrhizin, and araboglycyrrhizin, together with glycyrrhizin and 18 $\alpha$-glycyrrhizin and also of 49 kinds of phenolic compounds and their glycosides (11 then-new). The restoration-promoting activity of licorice-saponin B2 for $\mathrm{CCl}_{4}$-intoxicated hepatocyte function and the structure-sweetness relationship of saponins were discussed. Biologically interesting, but isolable in minor quantities, several licorice-saponins were favorably synthesized from abundantly available glycyrrhizin. With 15 saponins and 49 phenolic compounds (including their glycosides) at hand, chemical evaluation of licorice root processings was undertaken. It was shown that the cortex contained a rich amount of phenolic compounds, whereas the xylem was rich in phenolic glycosides and the saponins contained were richer in the xylem than in the cortex. It was also found that roasted licorice root contained an increased amount of glycyrrhetic acid monoglucuronide, which was secondarily formed from glycyrrhizin through thermal hydrolysis and was known to taste 5 times sweeter than glycyrrhizin.
\end{abstract}

\section{INTRODUCTION}

Licorice root (kanzou) is used worldwide as a natural sweetener, as well as a flavoring additive in various cases [1]. The botanical origin generally belongs to Glycyrrhiza sp. of Leguminosae. On the other hand, "Glycyrrhizae radix", a Chinese natural medicine (so-called crude drug) prepared from the airdried root of various Glycyrrhiza sp. [2] is most frequently prescribed as an important ingredient in many prescriptions of traditional Chinese medicine (Kampou medicine). For instance, in Chinese medicine in Japan, 108 out of 147 common prescriptions (73.5 \%) comprise Glycyrrhizae radix (\% weight in each prescription ranges ca. 3-100). It is described in Shao-Han-Lun (established during the later Han Dynasty, in China) that G. radix (1) harmonizes all drugs and detoxifies the adverse effects of herbs, (2) is used as a flavoring agent to mollify various drugs and to treat coughs and sore throat, (3) works synergetically with other drugs, and (4) has a hepatinica as well as a detoxifying action.

It is noted that $G$. radix in Chinese medicine is employed as an air-dried and sliced specimen or, in some cases, as a roasted specimen (baked with honey, in some cases) (so-called processed specimen, shuchi-kanzou). Japanese pharmacopoeia prescribes that G. radix may be prepared from the simply airdried whole root (underground part) or from the root after removing the root-bark (cortex) (another type of processed specimen, kawasari-kanzou) of Glycyrrhiza uralensis, G. glabra, or related spp. From medicinal viewpoints, it should be pointed out that chemical characterization to differentiate these

*Pure Appl. Chem. Vol. 74, No. 7, 2002. A special topic issue on the science of sweeteners. 
processed and unprocessed G. radix is essential. Especially, some years ago, when we initiated the chemical characterization studies of various G. radix, most studies until then in Japan were those undertaken on the chemical constituents of G. radix, which were imported from China as Chinese natural medicines (crude drugs) designated only with names of the harvested area (e.g., tohoku-kanzou from the northeastern region of China; seihoku-kanzou from the northwestern region of China; or shinkyokanzou from the Xinjiang district of China, etc.) but lacking distinct botanical indentification. Fortunately for us, it became possible to carry out pharmacochemical analyses of Chinese licorice roots (original plants of various G. radix) botanically identified in collaboration with Prof. Jiali Ren, the Xinjiang Institute of Chemistry, Academia Sinica, Wulumuqi, China. The works were started by investigating in detail the chemical constituents of several botanically identified kinds of licorice roots, i.e., G. inflata, G. uralensis, G. glabra, and G. aspera from Xinjiang and G. uralensis from the northeastern region of China.

This paper reviews our investigations thus far, together with some recent examinations on the chemical characterizations which were brought about through the processings of those licorice roots.

\section{CHEMICAL CONSTITUENTS OF SEVERAL KINDS OF LICORICE ROOTS}

Since licorice roots have been widely used for a variety of purposes, the chemical constituents were the subjects of many investigations, and various flavonoids and their glycosides have been identified [3]. As for the other major ingredients when our studies were started, glycyrrhizin (1) was the only saponin constituent, although several oleanene-type triterpenoids were identified from the hydrolysates of glycosidic mixtures of European Glycyrrhiza plants [3].

During our studies, we have identified 13 then-new saponins (all glucuronide-saponins, named licorice-saponins (LS-) A3 (2) [4], B2 (3) [4], C2 (4) [4], D3 (5) [5], E2 (6) [5], F3 (7) [5], G2 (8) [5], H2 (9) [5], J2 (10) [5], K2 (11) [5], L3 (12) [6], [attached numbers (2 3) indicated the number of monosaccharide moieties in the respective carbohydrate chains], apioglycyrrhizin (14) [7], and araboglycyrrhizin (15) [7] together with glycyrrhizin (1) and 18 $\alpha$-glycyrrhizin (13), and 49 kinds of phenolic compounds (including glycosides) (11 then-new) [6,8,9]. Among those licorice-saponins, LS-B2 (3) was shown to promote restoration of hepatocyte function in $\mathrm{CCl}_{4}$-intoxicated rats (both in vitro and in vivo) [10] (Fig. 1).

Glycyrrhizin (1), an efficient sweetening agent, is a representative glucuronide-saponin of licorice root, and the sweetness of 12 newly identified glucuronide-saponins was examined in comparison with glycyrrhizin (1). It was interesting to find that LS-B2 (3) (=11-deoxoglycyrrhizin) tasted bitter, while LS-A3 (2) showed a pleasantly sweet taste, but the degree of sweetness was one-half of glycyrrhizin (1). Additional findings of keen interest were that apioglycyrrhizin (14) was shown to be 300 times sweeter than sucrose, whereas araboglycyrrhizin (15) was shown to be as sweet as glycyrrhizin (1), which was known to be 150 times sweeter than sucrose [7] (Fig. 2). 

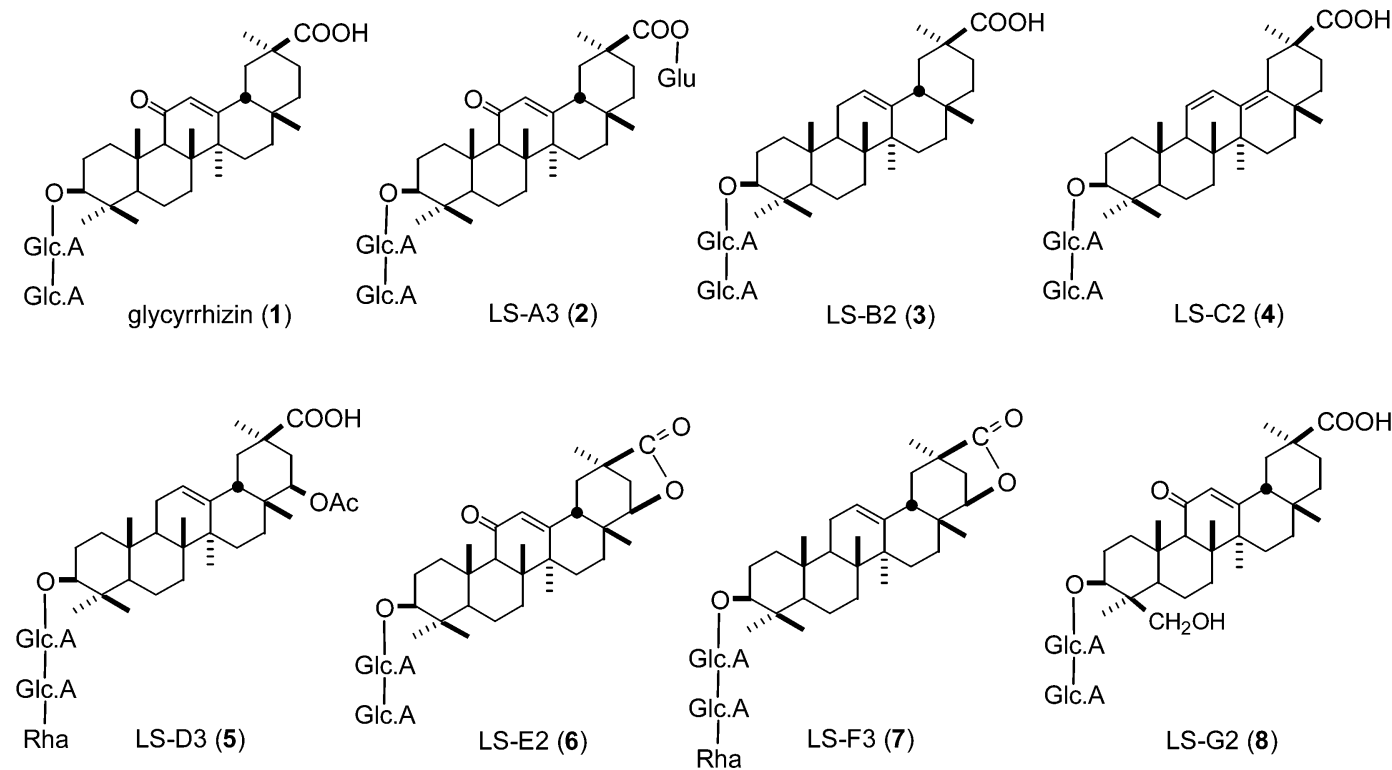

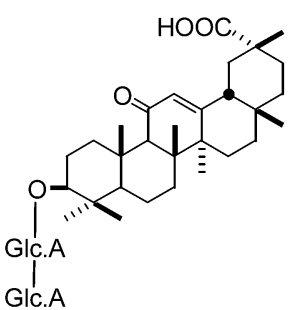

LS-H2 (9)

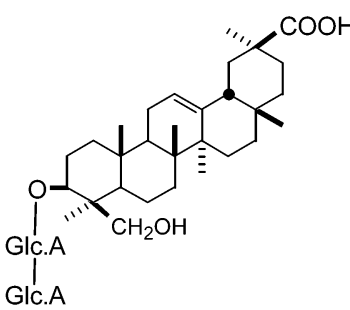

LS-J2 (10)

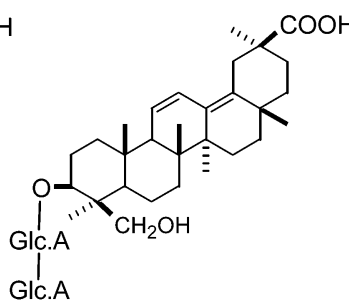

LS-K2 (11)

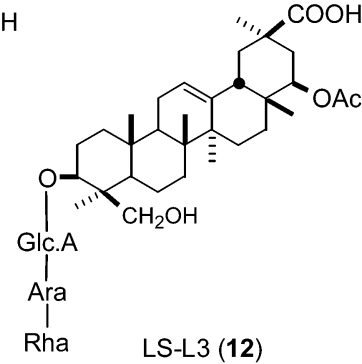

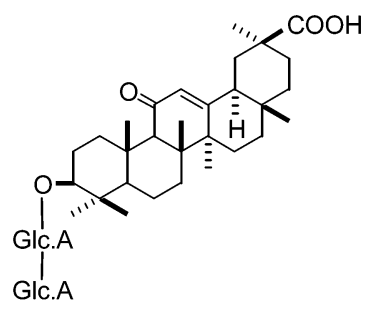

$18 \alpha-$ glycyrrhizin (13)

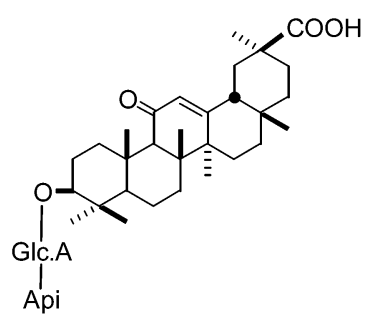

apioglycyrrhizin (14)

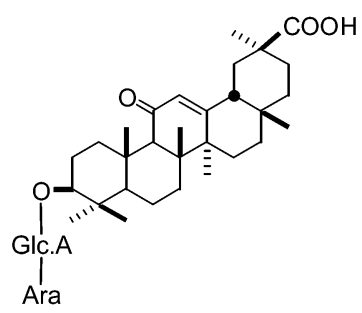

araboglycyrrhizin (15)

$$
\left[\begin{array}{c}
\text { LS : licorice-saponin } \\
\text { Ara : arabinose } \\
\text { Api : apiose } \\
\text { Glc.A : glucuronic acid } \\
\text { Glu : glucose } \\
\text { Rha : rhamnose }
\end{array}\right]
$$

Fig. 1 Licorice root saponins. 


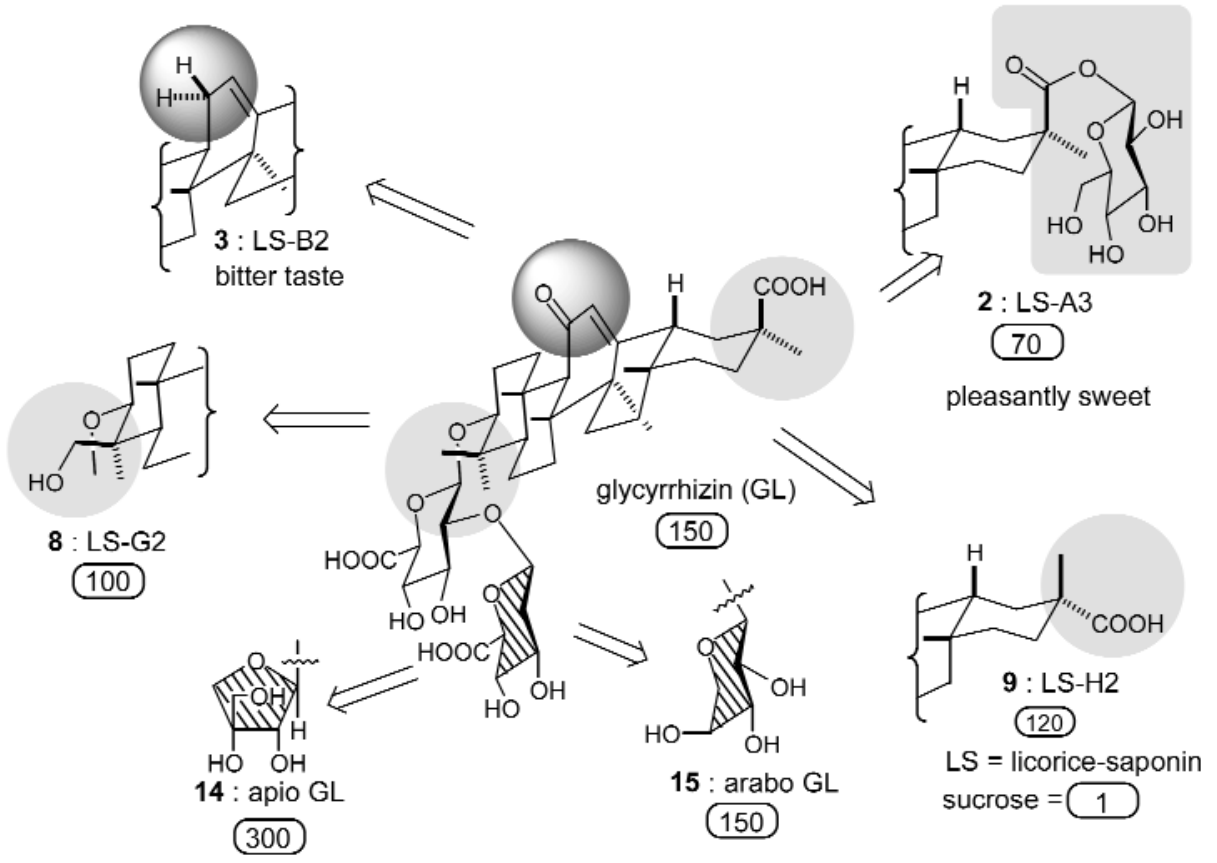

Fig. 2 Comparisons of sweetness.

\section{CHEMICAL CONVERSIONS OF GLYCYRRHIZIN AND ANALOGS}

Throughout the structure elucidation studies of those glucuronide-saponins, glycyrrhizin (1) was often utilized as the core compound. Abundantly available glycyrrhizin was also used as a supply for preparing the other biologically active glucuronide saponins. For example, since quantities of LS-B2 (3) were required for extensive pharmacological studies of LS-B2 and its analogs, as well as to confirm the structures of LS-B2 (3) and LS-C2 (4), versatile chemical conversions from glycyrrhizin (1) were devised [4]. Namely, a synthesis of $\mathbf{3}$ from $\mathbf{1}$ was successfully carried out by use of Clemmensen reduction, where treatment of $\mathbf{1}$ with zinc-amalgam and hydrochloride in dioxane and water at $10{ }^{\circ} \mathrm{C}$ provided $\mathbf{3}$ in $75 \%$ yield (Fig. 3).

Related correlations were also effected between LS-D3 (5) and LS-F3 (7), and between G2 (8) and $\mathrm{J} 2$ (10) or K2 (11) [5]. Thus, alkaline hydrolysis of 5 with $10 \%$ potassium hydroxide and subsequent treatment of the product with acidic resin furnished 7, exclusively. The Clemmensen reduction of $\mathbf{8}$ gave 10, whereas treatment of $\mathbf{8}$ with sodium borohydride under reflux and subsequent treatment of the product with dioxane-water under reflux furnished $\mathbf{1 1}$ in high yield. The emphasis made here was that all these chemical correlations were carried out in the respective glycoside forms, i.e., without previous protection as well as subsequent deprotection of the carbohydrate portions (Fig. 4). 


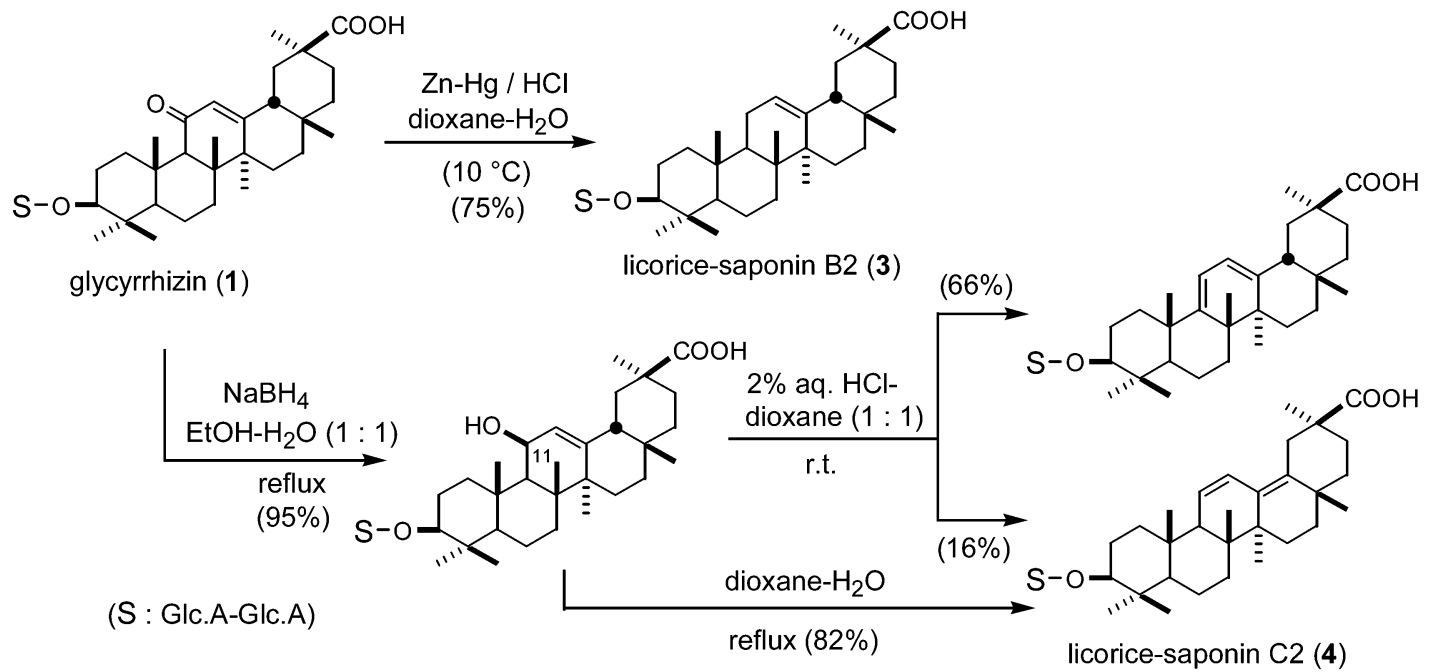

Fig. 3 Chemical conversions from glycyrrhizin.

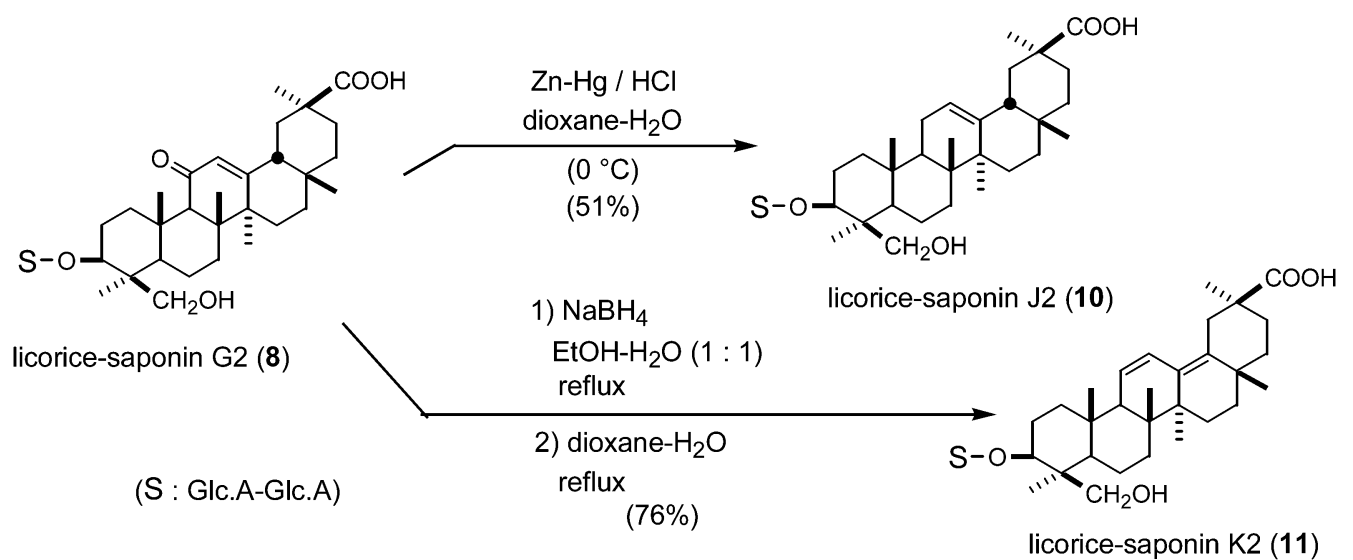

Fig. 4 Chemical correlations between LS-G2 and LS-J2, LS-G2, and LS-K2.

\section{CHEMICAL BASIS FOR LICORICE ROOT PROCESSINGS}

\section{Crude drug processings}

In Chinese traditional medicine, prescribed herbal medicines (crude drugs) are often those pretreated with appropriate processings beforehand. Thus, the processings constitute a very important segment of Chinese traditional medicine. The procedures of processings for individual herbal medicines were those being devised during the progress of Chinese traditional medicine, and those have been conveyed nowadays as the conventional and traditional pharmaceutical technology.

Crude drug processings comprise a variety of methods from the technical point of view, and those procedures are classified as:

- $\quad$ physical processing (removing outer layer, nodes, peels, cores, etc. in many cases);

- $\quad$ water processing (washing, dripping, soaking, etc.: e.g., for pinellia, salted aconite, etc.); 
- $\quad$ fire processing (roasting, broiling, charring, frying, etc.: e.g., for licorice, rehmannia, etc.);

- water and fire processing (boiling, steaming, scalding, etc.: e.g., for red ginseng, rehmannia, aconite, etc.); or

- $\quad$ other processings (e.g., burning, defatting, fermenting, lime treating, etc.).

The aims of those processings are said to

- $\quad$ reduce side-effects (e.g., for aconite, pinellia, strychnos);

- $\quad$ change qualities (e.g., for rehmannia, peony, ginger);

- $\quad$ increase pharmaceutical functions (e.g., for licorice);

- $\quad$ remove impurities and unwanted part (e.g.. for moutan);

- $\quad$ impart flavor and color (e.g., for red ginseng);

- $\quad$ facilitate administration; and

- $\quad$ increase purity.

The medicinal significance of processings has been recognized from clinical experiences, however, there remain yet many ambiguous matters to be solved. Our studies have focused on extensive chemical comparisons of the bioactive constituents in those herbal medicines before and after processings, in anticipation of finding new bioactive substances which may be formed secondarily during the processing procedures. In this connection, we have so far found various interesting compounds: for example, (a) ginsenoside $\mathrm{Rh}_{2}$ (a dammarane triterpene-glucoside of growth inhibiting against tumor cells) from red ginseng [11]; (b) ginsenoside $\operatorname{Rg}_{3}$ (16) (a dammarane triterpene-diglucoside of inhibiting tumor-cell invasion in vitro [12a,b,c] and in vivo [12d,e]) from red ginseng; (c) lipo-alkaloids (analgesic and antiinflammatory aconitine-alkaloids with less toxicity) from aconite root [13]; and (d) rehmaionosides A and B (ionone-glucosides inhibiting for noradrenaline-induced contraction of uretha smooth muscle) from rehmannia root [14]. Of these findings, it should be commented that ginsenoside $\operatorname{Rg}_{3}(\mathbf{1 6})$ has been recently developed as an anticancer drug in China (2000).

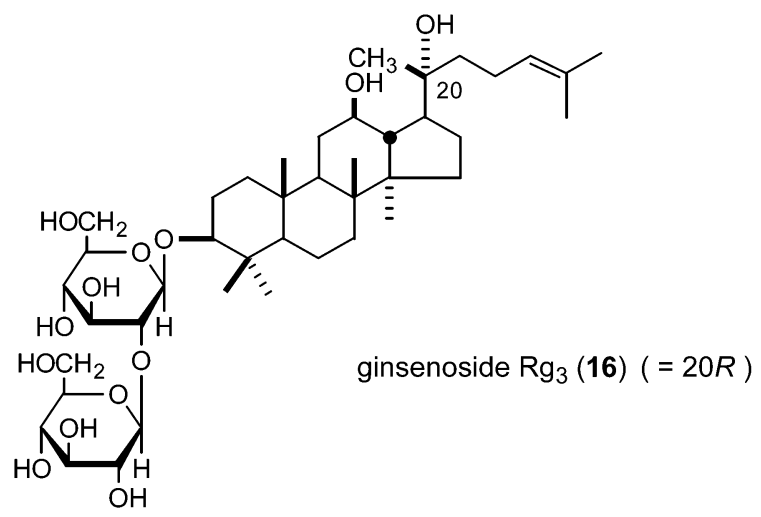

\section{Licorice root processings}

To shed light on the significance of licorice root processings, at first, the location of various constituents in the tissue of licorice root was examined. Through our extensive studies, roughly speaking, it became clear that the methanolic extracts of total licorice roots comprise phenolic compounds (flavonoids, coumarins, etc.) and their glycosides (cf. Fig. 5), and saponins [glycyrrhizin (1), licorice-saponins, etc.] (cf. Fig. 1).

With 15 kinds of saponins and 49 phenolic compounds (including their glycosides) at hand, the chemical evaluation of licorice roots was next undertaken by means of high-performance liquid chro- 
<smiles>[R]Oc1ccc([C@@H]2CC(=O)c3ccc(O)cc3O2)cc1</smiles>

liquiritin (17) : $\mathrm{R}^{1}=\mathrm{Glu}$ liquiritin apioside (18): $R^{1}=G A$ liquiritigenin (19): $\mathrm{R}^{1}=\mathrm{H}$<smiles>CC(C)=CCc1cc2c(=O)cc(-c3ccc(O)cc3)oc2cc1O</smiles>

licoflavone A (25)<smiles>[R20]c1cc2oc(=O)c(-c3ccc(O)cc3O)cc2c(OC)c1CC=C(C)C</smiles>

glycycoumarin (28): $\mathrm{R}^{4}=\mathrm{H}$ glycyrin (29): $\mathrm{R}^{4}=\mathrm{CH}_{3}$<smiles>[R20]Oc1ccc(/C=C/C(=O)c2ccc([R20])cc2O)cc1</smiles>

$\left[\begin{array}{l}\mathrm{Glu}=\beta \text {-D-Glu } \\ \mathrm{GA}=\beta \text {-D-Glu } 2-\mathrm{D}-\mathrm{Api}\end{array}\right]$<smiles>C=CC(C)(C)c1cc(/C=C/C(=O)c2ccc(O)cc2)c(O)cc1OC</smiles>

licochalcone A (26)<smiles>COc1c(CC=C(C)C)c(O)cc2oc(=O)c3c4ccc(O)cc4oc3c12</smiles>

glycyrol (30) neoisoliquiritin (20): $\mathrm{R}^{2}=\mathrm{Glu}, \mathrm{R}^{3}=\mathrm{H}$ isoliquiritin (21): $R^{2}=H, R^{3}=$ Glu isoliquiritin apioside (22): $R^{2}=H, R^{3}=G A$ licuraside (23): $R^{2}=G A, R^{3}=H$ isoliquiritigenin (24): $\mathrm{R}^{2}=\mathrm{H}, \mathrm{R}^{3}=\mathrm{H}$

Fig. 5 Phenolics and their glycosides in G. uralensis from the northeastern region of China.

\section{Preparation of Sample}

Licorice Roots (powder, $5 \mathrm{~g}$ )

$$
\begin{aligned}
& \text { 1) } 90 \% \text { aq. } \mathrm{MeOH}(50 \mathrm{ml}) \\
& \text { reflux for1 hr, } 3 \text { times } \\
& \text { 2) filt. and evap. in vacuo }
\end{aligned}
$$

$\mathrm{MeOH}$ ext. / $50 \%$ aq. EtOH $(50 \mathrm{ml})[=$ sample $\mathrm{A}]$

\section{flavonoids \& flavonoid glycosides}

$10 \mathrm{ml}$

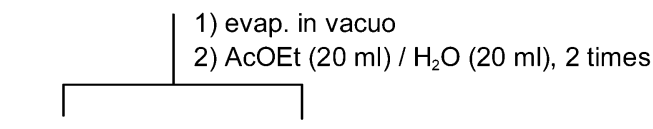

$\mathrm{H}_{2} \mathrm{O}$ phase AcOEt phase

1) evap. in vacuo

2) dissolve in $50 \%$ aq. EtOH (50 ml)

sample B saponins

\section{Conditions}
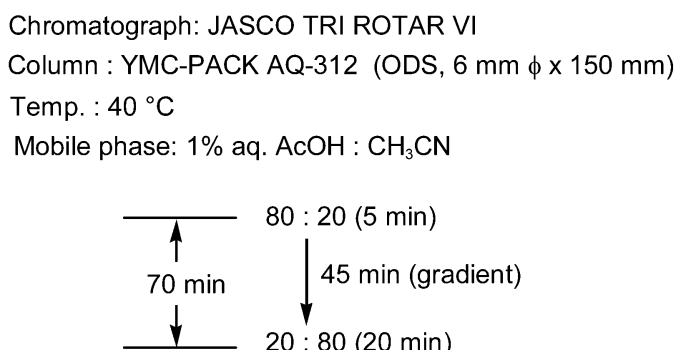

Flow rate: $1 \mathrm{ml} / \mathrm{min}$

Detector: Shimadzu Photodiode Array UV-VIS SPD- M6A or JASCO UVIDEC 100-VI

Detection: UV $254 \mathrm{~nm}$ (sample A, B) $350 \mathrm{~nm}$ (sample A)

Fig. 6 HPLC analysis of licorice root constituents.

matography (HPLC), which effected quantitative analyses of both saponin and phenolic constituents simultaneously [15] (Fig. 6). Some examples were shown for the roots of $G$. inflata from the Xinjiang district of China (Fig. 7). 


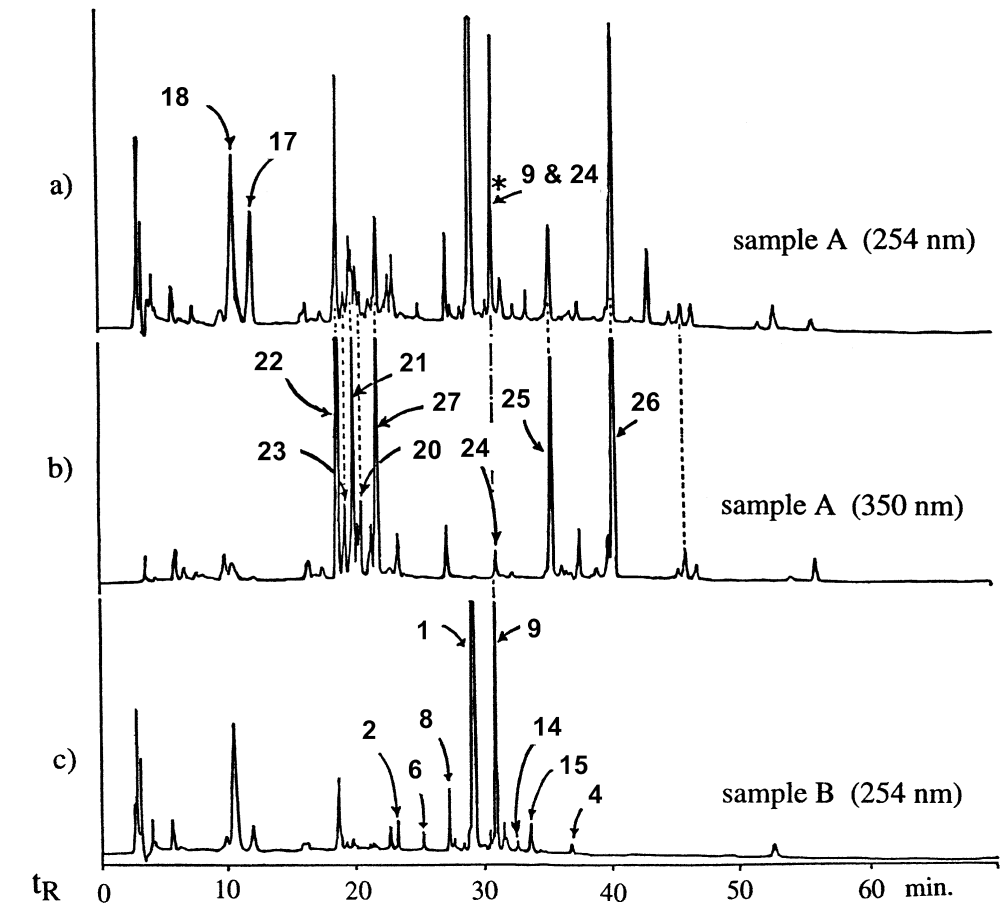

Fig. 7 HPLC diagrams for samples A and B from the roots of G. inflata (from the Xinjiang district of China).

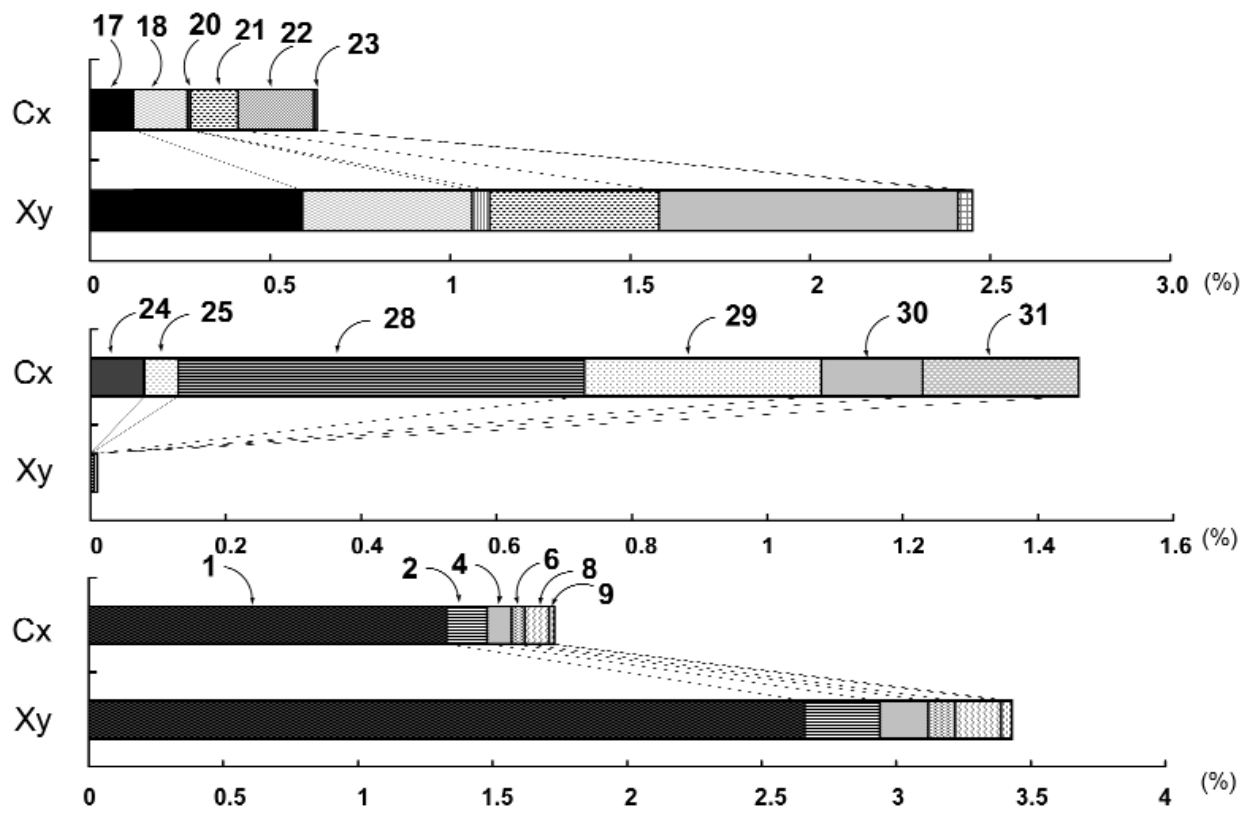

Fig. 8 Distribution of constituents in different tissues of G. uralensis from the northeastern region of China (Cx: cortex, Xy: xylem). 
Then, the root of G. ularensis was divided into cortex and xylem, and the respective constituents were analyzed. The cortex was shown to contain a rich quantity (1.46\%, but trace in xylem) of phenolic compounds (e.g., 24, 25, 28, 29, 30, 31), while the xylem was rich $(2.45 \%$ in xylem, but $0.63 \%$ in cortex) in phenolic glycosides (e.g., 17, 18, 20, 21, 22, 23). As for the saponin constituents, the xylem contained a richer amount $(3.43 \%)$ of glycyrrhizin (1) and licorice-saponins (e.g., 2, 4, 6, 8, 9) than the cortex (1.73\%) (Fig. 8) [16].

Finally, by the HPLC analytical method, chemical constituents in Chinese licorice roots, unprocessed and processed, were quantitatively determined in a comparative manner. It was confirmed that nonglycosidic phenolic constituents were mostly lost when the root bark (cortex) was removed, whereas, in the roasted (baked) licorice roots, sugar chains in glycyrrhizin (1) and glycosidic phenolic constituents were hydrolyzed stepwise from the terminal sugar moieties during roasting, presumably through hydrothermolysis [16]. Namely, $\mathbf{1}$ in licorice roots was decomposed while roasting to glycyrrhetic acid monoglucuronide (32) and then to glycyrrhetic acid (33). It was an interesting finding regarding the significance of roasting licorice root that $\mathbf{3 2}$ derived from $\mathbf{1}$ was known to be 5 times sweeter than 1 [17] and was reported to exhibit significant cancer-preventing activity [18].

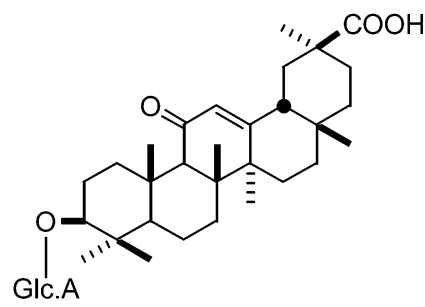

glycyrrhetic acid monoglucuronide (32)

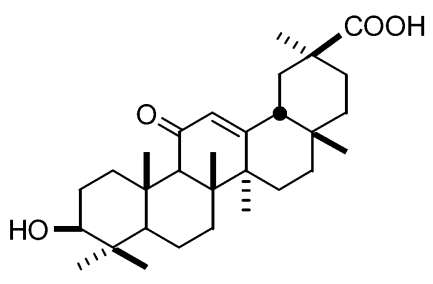

glycyrrhetic acid (33)

\section{ACKNOWLEDGMENTS}

The author thanks Dr. G. Tanabe and Prof. O. Muraoka, Kinki University, for their generous assistance for preparation of the presentation.

\section{REFERENCES}

1. O. Tanaka. "Sweet glycosides in molecular recognition in taste and odor", (review in Japanese) Kikan Kagaku Sosetu 40, 35-49 (1999), ed. by Chemical Society of Japan, Tokyo.

2. S. Shibata. "A drug over the millennia: Pharmacognosy, chemistry, and pharmacology of licorice" (review in English), Yakugaku Zasshi, 120, 849-862 (2000), Pharmaceutical Society of Japan, Tokyo.

3. T. Nomura and T. Fukai. Fortschritte der Chemie Organischer Naturstoffe, Bd. 73, W. Herz, G. W. Kirby, R. E. Moore, W. Steglich, Ch. Tamm (Eds.), pp. 1-140, Springer, New York (1998).

4. I. Kitagawa, K. Hori, T. Taniyama, J.-L. Zhou, M. Yoshikawa. Chem. Pharm. Bull. (Tokyo) 41, 43-49 (1993).

5. I. Kitagawa, K. Hori, M. Sakagami, J.-L. Zhou, M. Yoshikawa. Chem. Pharm. Bull. (Tokyo) 41, 1337-1345 (1993).

6. I. Kitagawa, K. Hori, E. Uchida, W.-Z. Chen, M. Yoshikawa, J. Ren. Chem. Pharm. Bull. (Tokyo) 41, 1567-1572 (1993).

7. I. Kitagawa, K. Hori, M. Sakagami, F. Hashiuchi, M. Yoshikawa, J. Ren. Chem. Pharm. Bull. (Tokyo) 41, 1350-1357 (1993). 
8. I. Kitagawa, W.-Z. Chen, K. Hori, E. Harada, N. Yasuda, M. Yoshikawa, J. Ren. Chem. Pharm. Bull. (Tokyo) 42, 1056-1062 (1994).

9. I. Kitagawa, W.-Z. Chen, K. Hori, M. Kobayashi, J. Ren. Chem. Pharm. Bull. (Tokyo) 46, 1511-1517 (1998).

10. Y. Ohba and I. Kitagawa. Preliminary pharmacological examination.

11. a) S. Odashima, T. Ohta, H. Kohno, T. Matsuda, I. Kitagawa, H. Abe, S. Arichi. Cancer Res. 45, 2781-2784 (1985); b) T. Ohta, K. Fujiwara-yamamoto, Z. Zong, M. Yamazaki, S. Odashima, I. Kitagawa, H. Abe, S. Arichi. Cancer Res. 47, 3863-3867 (1987).

12. a) I. Kitagawa, H. Shibuya, H. Akedo, K. Shinkai, M. Mukai. Ginseng Rev. 14, 14-17 \& No. 15, 29-33 (1992) (in Japanese); b) I. Kitagawa, H. Akedo, K. Shinkai, M. Mukai. Ginseng Rev. 16, 16-20 (1993) (in Japanese); c) I. Kitagawa, M. Kobayashi, H. Akedo, K. Shinkai, M. Mukai, F. Imamura, Ginseng Rev. 18, 33-36 (1994) (in Japanese); d) I. Kitagawa, M. Kobayashi, H. Akedo, M. Tatsuta, H. Iishi, K. Shinkai, M. Mukai, F. Imamura. Ginseng Rev. 20, 41-46 (1995) (in Japanese); e) K. Shinkai, H. Akedo, M. Mukai, F. Imamura, A. Isoai, M. Kobayashi, I. Kitagawa. Jpn. J. Cancer Res. 87, 357-362 (1996); f) H. Iishi, M. Tatsuta, M. Baba, H. Uehara, A. Nakaizumi, K. Shinkai, H. Akedo, H. Funai, S. Ishigura, I. Kitagawa. Clin. Exp. Metastasis 15, 603-611 (1997).

13. I. Kitagawa, Z. L. Chen, M. Yoshihara, K. Kobayashi, M. Yoshikawa, N. Ono, Y. Yoshimura. Yakugaku Zasshi 104, 858-866 (1984) (in Japanese).

14. K. Nakase, I. Kimura, M. Kimura, I. Kitagawa. Phytotherapy Res. 5, 67-71 (1991).

15. I. Kitagawa, W.-Z. Chen, T. Taniyama, E. Harada, K. Hori, M. Kobayashi, J. Ren. Yakugaku Zasshi 118, 519-528 (1998) (in Japanese).

16. H. Kuwajima, Y. Taneda, W.-Z. Chen, T. Kawanishi, K. Hori, T. Taniyama, M. Kobayashi, J. Ren, I. Kitagawa. Yakugaku Zasshi 119, 945-955 (1999) (in Japanese).

17. T. Kuramoto and S. Yamamoto. Shokuhin Kogyoh 33, 46-50 (1990) (in Japanese).

18. K. Mizutani. New Food Industry 40, 1-10 (1998) (in Japanese). 